\title{
The psychiatric Münchausen
}

\author{
DAVID I. BEN-TOVIM \\ M.B. B.S., M.R.C.Psych. \\ Department of Adult Psychiatry, St George's Hospital, Blackshaw Road, London, S.W.17.
}

\begin{abstract}
Summary
Two cases of patients with the Münchausen syndrome who sought admission for fictitious psychiatric illnesses are presented - one case involves an accomplice. The patients' authentic life histories are used in the discussion of the syndrome's aetiological factors.

\section{Introduction}

Two cases of the Münchausen syndrome, as defined by Blackwell (1965) and Spiro's (1968) criteria of (1) wide travel, (2) extravagant and persistent lying, (3) dramatic presentation of a feigned medical or surgical illness, are reported, both of whom claimed they were suffering from fictitious psychiatric illnesses. Such a presentation of the syndrome has not been previously described and indeed the first case is even more unusual in that an accomplice was involved: there is only one other report in the literature (Steinbeck, 1961) of a second party's knowing involvement in the Münchausen's deceptions.
\end{abstract}

\section{Case reports}

Case 1

Miss N, aged 23 years, presented herself to the Casualty Department of the hospital where the author was then working, having taken a salicylate overdose, and was eventually transferred, as a voluntary patient, to the psychiatric unit. She said that her overdose had been an impulsive gesture precipitated by her husband, a solicitor, leaving her and she claimed that recently, with her 2-year-old marriage deteriorating, she had become depressed, with accompanying symptoms of anorexia, weight loss of $6.35 \mathrm{~kg}$ and amenorrhoea. She denied any significant past medical or psychiatric history.

The vivid and detailed description of her life that she gave on admission was confirmed by a young woman who claimed to be her heterozygous twin and indeed there was some facial resemblance between the two women, although the patient was of a slighter build. This 'twin' visited the unit a number of times subsequently, but then disappeared.

During her stormy 3-month stay the patient was always taciturn and uncommunicative whilst on the ward, and her mood fluctuated being initially mildly euphoric, although later there were glimpses $\omega_{\sigma}$ of a profound despair. Her behaviour graduallyo became increasingly disturbed and there were 3 episodes of wrist slashing and petty thieving. Eventually she took a glutethimide overdose and + required assisted ventilation for $48 \mathrm{hr}$, and as $\mathbb{\infty}_{\infty}$ attempts were made to inform her relatives of her ${ }_{\infty}^{\infty}$ condition her deceptions became apparent. Her $\vec{\infty}$ parents, with whom she claimed to have lost contacto at the age of 17.5 years were interviewed and $a_{-}$ correct history obtained.

Miss $\mathbf{N}$ had told a complex mixture of lies and $\stackrel{\mathbb{D}}{\circ}$ exaggerations; she did not, in fact, have a twin; $\frac{\mathbb{D}}{3}$ her visitor was just a friend who was herself receiving psychiatric care, and her mother, who was said $\mathbb{C}^{-}$ be a Principal Nursing Officer, was in fact a State- $\overrightarrow{0}$ enrolled nurse. Indeed Miss $\mathrm{N}$ and her mothe had started nursing training together but Miss was dismissed after 8 months because of thefts from colleagues. She had never been married, and had probably never had a serious sexual relationship. The parents also revealed that although they had $\mathbb{Q}$ violently quarrelled between themselves over the years, they had doted on Miss $\mathrm{N}$ who had been $\mathrm{a}$ 윽 very beautiful child, but with a tendency to exaggeration. They said that the patient had had two previous conventional admissions to psychiatric hospitals, once for 'depression' and once to a 3 hospital specializing in the treatment of personality disorders, but that in the last 4 months a pattern of 3 . overdose and then self-discharge had taken her from hospital to hospital throughout London. 3 Although she had used different pseudonyms, it was 0 possible to confirm at least three such admissions. The only precipitant appeared to have been dismissal from a job as a nanny (she had claimed that her occupation was 'writer of romantic fiction').

Although she stayed with the unit for a further $N$ fortnight after 'discovery', she remained guarded N about her motives and eventually discharged herself. $\sigma$ Over the next few weeks the unit heard of two

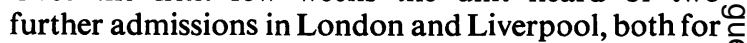
overdoses 'precipitated' by fictitious rows with fictitious boy friends, but since then contact with her has been lost. 


\section{Case 2}

Although the unit's experiences with the second patient are described below, details of his admission to a neighbouring psychiatric unit which has made its records available to the author will first be given.

$\mathrm{Mr} \mathrm{C}$, aged 35 years, was admitted to another hospital following an overdose of tricyclic antidepressants and, on arrival, gave a classical history of affective illness with: onset at 25 years old; periodic mood swings usually responsive to medication, but once requiring admission and ECT in Germany; a positive family history of father and an uncle both suffering from affective illness. He said that his present complaint was of a deepening depression of 3 weeks' duration and he described diminished libido, concentration and appetite. He also complained of subjective slowing of his mental processes, but neither on admission nor during the 2 days before he absconded was there any objective evidence of motor retardation or altered mood. Indeed, when his father was interviewed subsequently it became clear that the whole history that $\mathrm{Mr} \mathrm{C}$ had given was an elaborate fabrication.

In reality, Mr C's mother had died of pneumonia when he was 3 years old, and until the age of 8 years he had been brought up by a loving grandmother. However, his father remarried and $\mathrm{Mr} \mathrm{C}$, whose dishonesty was already apparent, clashed with his stepmother and he was sent to boarding preparatory and secondary schools, leaving at the age of 18 years with several ' $O$ ' and two ' $A$ ' levels. His work history was sporadic and he has been prosecuted for a variety of minor financial offences. He was married when 22 years old and separated 3 years later and he has been a heavy drinker since he was 18 years old.

His hospital 'career' started in the year after the break-up of his marriage. He has used the dramatic ploy of collapsing in the street with an hysterical paresis to gain admission to at least six hospitals, including twice to St George's, London, and thus the affective illness, described above, represents a new 'ticket of entry'.

He has used a variety of pseudonyms over the years and given varying life histories. He usually says his parents are German Jews, although he once described his father as a Nazi war criminal. He frequently gives himself a university degree and a successful business career and he never discloses either his drinking or criminal history.

Usually, when confronted with discrepancies in his life history he makes further wild claims before discharging himself, e.g. he once said that he lied because he was actually an 'a.w.o.l.' Israeli army major. However, in the latest recorded admission, he stayed some weeks under his own name, but during treatment broke the terms of a probation order and was imprisoned.

\section{Discussion}

The patients presented above differ from those presented in previous reports of the Münchausen syndrome in that a functional and not an organic illness is mimicked although they are faithful to the other pathognomonic characteristics of the syndrome, namely restless wandering, flamboyant lying and self-destructiveness (Barker, 1967). Given those characteristics it is not surprising that there are very few other cases with reliable second informants to the patients' life-histories (Ireland, Sapira and Templeton, 1967) so that availability of Miss $\mathrm{N}$ and $\mathrm{Mr}$ C's parents' observations represents an opportunity to review those aetiological factors that may be specific to the disorder.

Both of the patients' later tendency to lie and exaggerate was noticeable from an early age (5 and 8 years respectively) and indeed during their early childhood both experienced a complex mixture of parental doting and disruption due to loss or strife. This mixture is not uncommon, being reported by Ford (1973), Spiro (1968) and Blackwell (1965) and may help to set the scene for the later tendency towards imposture, a grande facade concealing an impoverished self-image (Deutsch, 1955) in both patients. Unfortunately, because of the limited period of observation the motives of Miss N's impostored twin remain obscure.

Cramer, Gershberg and Stern (1971) have speculated that the Münchausen syndrome represents a later re-enactment of traumatic early experiences with doctors or hospitals, but the case-material presented here only partially validates this. $\mathrm{Mr} \mathrm{C}$ had no early medical contact and Miss N's, although painful, was in her teens.

However, it does seem noteworthy that both the cases were precipitated into their hospital 'career' after a separation from a source of stability, Miss $\mathrm{N}$ from her job as a nanny and $\mathrm{Mr} \mathrm{C}$ after leaving his wife. This pattern is not uncommon and can be seen in five other cases: three on marital breakdown (Clarke and Melnick, 1958; Blackwell, 1965; Spiro, 1968): one whenever left by his mother (Ford, 1973), and one following bereavement (Himsworth et al., 1974) whose whole behaviour resembled an abnormal grief reaction (Parkes, 1965).

Finally, the fact that Miss N's behaviour started despite early intensive psychiatric treatment for her personality disorder serves to underline how much more knowledge is required before effective treatment can be initiated.

\section{Acknowledgments}

I would like to thank $\mathrm{Dr} \mathrm{O}$. Hill and Professor $\mathrm{M}$. 
Shepherd for permission to publish their cases and Dr D. Somekh for helping me locate information on the second case.

\section{References}

BARKER, J.C. (1967) The Münchausen or hospital addictions syndrome. In: Some Uncommon Psychiatric Syndromes, Enoch, M.D., Trethowan, H. \& Barker, J.C. John Wright, Bristol.

BlacKWell, P. (1965) Münchausen at Guy's. Guy's Hospital Reports, 114, 257.

Clarke, E. \& Melnick, S.C. (1958) The Münchausen syndrome or the problem of hospital hoboes. American Journal of Medicine, 25, 6.

Cramer, B., Gershberg, M.R. \& Stern, M. (1971) Münchausen syndrome: its relation to malingering, hysteria, and the physician-patient relationship. Archives of General Psychiatry, 24, 573.
Deutsch, H. (1955) The impostor: contribution to the ego $\$ psychology of a type of psychopath. Psychoanalytic $\stackrel{\curvearrowright}{\&}$ Quarterly, 24, 483.

FORD, C.V. (1973) The Münchausen syndrome: a report of four new cases and a review of psychodynamic consider- $\overrightarrow{\vec{A}}$ ations. Psychiatric Medicine, 4, 31.

Himsworth, R.L., Bangham, C., Mason, A.M. \& Nixon, J. (1974) Has anyone else seen Betty? Lancet, i, 796.

Ireland, P., SaPira, J.D. \& Templeton, B. (1967) Münchausen syndrome: review and report of an additional case. American Journal of Medicine, 43, 579.

PARKes, C.M. (1965) Bereavement and mental illness: a classification of bereavement reactions. British Journal of Medical Psychology, 38, 13.

SPIRo, H.R. (1968) Chronic fictitious illness. Münchausen syndrome. Archives of General Psychiatry, 18, 569.

STEINBECK, A.W. (1961) Haemorrhagica histrionica - the bleeding Münchausen syndrome. Medical Journal of Australia, 48, 451. 